\title{
DIVERSIDADE DE BRIÓFITAS DE UMA ÁREA DE CAATINGA NA CHAPADA DO APODI-CEARÁ
}

\author{
$\underline{\text { Jacson Oliveira dos Santos }^{1}}{ }^{\text {; Emilia de Brito } \text { Valente }^{2}}$ \\ 1. Bolsista PIBIC/FAPESB, Graduando do Curso de Licenciatura em Ciências Biológicas, Universidade Estadual de \\ Feira de Santana, e-mail: jacson.oliveira.bio@gmail.com \\ 2. Orientador do Departamento de Ciências Biológicas, Universidade Estadual de Feira de Santana, e-mail: \\ ebvalente@gmail.com
}

PALAVRAS-CHAVE: Semiárido; Musgos; Hepáticas

\section{INTRODUÇÃO}

A Chapada do Apodi, possui $2608 \mathrm{~km}^{2}$ e está localizada entre os Estados do Rio Grande do Norte e Ceará, além de ser limitada pelo rio Apodi-Mossoró, a leste, e pelos rios Quixeré e Jaguaribe, a oeste, correspondendo aos domínios da Chapada do Apodi. A região hoje é considerada um grande polo econômico de exportação de frutas para Europa e América do Norte. (MIRANDA et al. 2012).

As Briófitas são plantas pequenas que frequentemente crescem em locais úmidos nas florestas tropicais ou ao longo das margens de curso d'água ou terras úmidas, possuem gametófitos independente nutricionalmente dos esporófitos, enquanto que o esporófito é dependente nutricionalmente do gametófito, possui ciclo de vida com a geração gametofítica dominante, necessidade de água para a reprodução sexuada, ausência de vasos condutores lignificados. (RAVEN et al. 1999). Elas são representadas pelas Hepáticas, Antóceros e Musgos, que correspondem respectivamente a Marchantiophyta, Anthocerophyta, Bryophyta (SHAW e GOFFINET, 2000).

Os trabalhos sobre diversidade de briófitas no Brasil ainda são muito escassos e quando parte para o semiárido brasileiro, esses estudos se mostram insuficientes. Segundo Pôrto (1996) em ambientes semiáridos do Nordeste brasileiro é evidente a escassez de publicações sobre a ocorrência de briófitas. Porém muitos pesquisadores vêm estudando essas áreas que se mostram promissoras em relação a diversidade de briófitas (Silva \& Germano, 2013; Valente et al, 2013; Valente, 2010; Oliveira, 2009; Pôrto, 1996; Pôrto, 1994). Mas esses estudos ainda se mostram tímidos quando comparado a outros grupos de plantas.

As briófitas contribuem significativamente para a diversidade vegetal e são também importantes em algumas partes do mundo pelas quantidades de carbono que armazenam, desempenhando papel importante no ciclo global do carbono (RAVEN et al. 1999). Além de possuírem grande potencial bioindicador, estando diretamente relacionadas com a qualidade do ar, bem como com alterações decorrentes da urbanização (CÂMARA, 2006). Diante de tamanha importância, faz-se necessário estudos e realização de inventários florísticos de briófitas em áreas desconhecidas, no intuito de colaborar com novas informações sobre a diversidade desse grupo de plantas e uma possível preservação da área estudada.

Esse trabalho teve como objetivo a promoção de uma ampliação do conhecimento acerca da composição florística e diversidade de briófitas da região do semiárido nordestino, na área da Chapada do Apodi.

\section{MATERIAL E MÉTODOS}

A área onde foi realizado o levantamento florístico fica localizada na faixa compreendida entre as cidades de Mossoró no Rio Grande do Norte e Limoeiro do Norte, no 
Ceará. Possui área de $2608 \mathrm{Km}^{2}$, sendo a maior parte localizada no Rio Grande do Norte, (1427 $\mathrm{Km}^{2}$ ) e restando $1181 \mathrm{Km}^{2}$ para o Ceará. O clima é do tipo semiárido, caracterizado pela ocorrência de duas estações distintas: uma de chuva, denominado de inverno, que possui duração de quatro meses e uma de estiagem, com duração de oito de meses. A vegetação predominante é Caatinga Hiperxerófila, mas a extração de madeira e a implantação do agronegócio vem destruindo a vegetação da área (MIRANDA, 2011).

As amostras foram coletadas e armazenadas segundo a metodologia proposta por Lisboa (1993): o material foi coletado aleatoriamente com auxílio de um canivete ou manualmente, e acondicionado em sacos de papel pardo, onde foram anotadas informações como local de coleta, substrato (corticícola - tronco de árvore viva; epíxila - árvore morta; rupícola - sobre rochas; terrestres - solo.), nome do coletor e o número da coleta. As amostras foram identificadas com o auxílio de lupa e microscópio e bibliografia especializada a exemplo GRADSTEIN \& COSTA, (2003); YANO, (2000); SHARP et al, (1994) BUCK, (1998).

Os sistemas de classificação adotados foram os de Goffinet et al. (2009) para musgos e Crandal-Stoller et al. (2009) para hepáticas. A análise da distribuição geográfica das espécies foi realizada a partir de consulta ao site da Flora do Brasil (2020) bem como publicações recentes.

\section{RESULTADOS}

No levantamento florístico realizado na Chapada do Apodi, Ceará. Foram encontradas 60 espécies de Briófitas, sendo sete famílias de Marchantiophyta com 27 e espécies e 14 famílias de Bryophyta com 33 espécies. As plantas foram encontradas crescendo em vários substratos, a comunidade por substratos mais encontradas foi do tipo cortícola. A família que mais apresentou riqueza de espécies foi a Lejeuneaceae com 13 espécies, seguido das famílias de Plagiochilaceae, Bryaceae, Pottiaceae com quatro espécies cada (Tabela 1 e 2). Dessas espécies encontradas, 16 foram consideradas novas ocorrências para o Estado do Ceará.

A maior parte das espécies estão distribuídas na região Neotropical e possuem uma ampla distribuição pelas regiões brasileiras, tendo as regiões Sul e Sudeste como as mais presentes. As espécies Cronisia weddellii, Lejeunea oligoclada, Brachymenium exile, Weisiopsis bahiensis, foram considerdas endêmicas do Brasil. Sendo que a espécie Weisiopsis bahiensis (Bryophyta) foi citada para a cidade de Oeiras no estado de Goiás por Yano, (1981), porém Oeiras fica situado no estado do Piauí. (COSTA, 2016). Também foram identificadas 33 espécies novas para o bioma Caatinga, sendo que a espécie Riccia subplana foi considerada nova ocorrência para o Nordeste. Dessa forma percebe-se a importância dos trabalhos florísticos de áreas ainda pouca pesquisadas, pois possibilita novas informações para a ciência, como a espécie $W$. bahiensis, que foi citada apenas uma vez para um estado brasileiro e a espécie $R$. subplana, considerada nova para o Nordeste, sendo agora citado para área da Chapada do Apodi, Ceará.

Tabela 1: Famílias de Marchantiophyta encontradas no levantamento florístico com quantidade de gêneros e espécies identificadas.

\section{FAMÍLIAS DE MARCHANTIOPHYTA TOTAL DE GÊNEROS E ESPÉCIES}

\begin{tabular}{ll}
\hline CEPHALOZIELLACEAE Douin & 1 gênero e 1 espécie \\
\hline CORSINIACEAE Engl & 1 gênero e 1 espécie \\
\hline FRULLANIACEAE Lorch & 1 gênero e 3 espécies \\
\hline LEJEUNEACEAE Cas.-Gil & 5 gêneros e 13 espécies \\
\hline METZGERIACEAE Raddi & 1 gênero e 2 espécies \\
\hline
\end{tabular}


PLAGIOCHILACEAE (Joerg.) K. Müll. 1 gênero e 4 espécies

RICCIACEAE L. 1 gênero e 3 espécies

Total: 11 gêneros e 27 espécies

Tabela 2: Famílias de Bryophyta encontradas no levantamento florístico com quantidade de gêneros e espécies identificadas.

\begin{tabular}{|c|c|}
\hline FAMÍLIAS DE BRYOPHYTA & TOTAL DE GÊNEROS E ESPÉCIES \\
\hline BRACHYTHECIACEAE Schimp. & 2 gêneros e 3 espécies \\
\hline BRYACEAE Schwägr. & 3 gêneros e 4 espécies \\
\hline CALYMPERACEAE Kindb. & 3 gêneros e 3 espécies \\
\hline CRYPHAEACEAE Schimp. & 1 gênero e 1 gênero \\
\hline FABRONIACEAE Schimp. & 1 gênero e 1 espécie \\
\hline FISSIDENTACEAE Schimp. & 1 gênero e 3 espécies \\
\hline LEUCOBRYACEAE Schimp. & 1 gênero e 2 espécies \\
\hline METEORIACEAE Kindb. & 2 gêneros e 2 espécies \\
\hline ORTHOTRICHACEAE Anr. & 2 gêneros e 2 espécies \\
\hline POTTIACEAE Schimp. & 4 gêneros e 4 espécies \\
\hline PTEROBRYACEAE Kindb. & 1 gênero e 2 espécies \\
\hline $\begin{array}{l}\text { PYLAISIADELPHACEAE Goffinet \& } \\
\text { W.R. Buck }\end{array}$ & 1 gênero e 1 espécie \\
\hline SEMATOPHYLLACEAE Broth. & 1 gênero e 2 espécies \\
\hline $\begin{array}{l}\text { STEREOPHYLLACEAE W.R. Buck e } \\
\text { Ireland }\end{array}$ & 2 gêneros e 3 espécies \\
\hline
\end{tabular}

Total

21 gêneros e 33 espécies

\section{CONSIDERAÇÕES FINAIS}

O levantamento florístico de áreas desconhecidas ou pouco estudadas é muito importante para o conhecimento da diversidade de plantas da área. O levantamento realizado na Chapada do Apodi foi importante, pois possibilitou a descoberta de novas informações sobre a vegetação da área.

\section{REFERÊNCIAS}

BUCK, W.R. 1998. Pleurocarpous Mosses of the West Indies. Memoirs of The New York Botanical Garden 1: 1-401.

CÂMARA, P. E., TEIXEIRA, R., LIMA, J., LIMA, J. Musgos urbanos do recanto das Emas, Distrito Federal, Brasil. Acta Botanica Brasilica, Dez 2003, vol.17, no.4, p.507-513. ISSN 0102-3306

COSTA, D. P. Synopsis of the Family Pottiaceae in Brazil, Phytotaxa, 2016, 251 (1): 001-069 CRANDALL-STOTLER. B.; STOTLER R.E. \& LONG, D.G. 2009. Morphology and classification of the Marchantiophyta. In: GOFFINET, B. \& SHAW, A.J. (Eds.). Bryophyte Biology. $2^{\mathrm{a}}$ ed. Cambridge, Cambridge University Press.

Flora do Brasil 2020 em construção. Jardim Botânico do Rio de Janeiro. Disponível em: < http://floradobrasil.jbrj.gov.br/ >. Acesso em: 03 Ago. 2017 
GRADSTEIN, S.R. \& COSTA, D.P. 2003. The Hepaticae and Anthocerotae of Brazil. Memoirs of The New York Botanical Garden 87: 1-318.

GOFFINET, B.; BUCK, W.R. \& SHAW, A. J. 2009. Morphology, anatomy, and classification of the Bryophyta. In: GOFFINET, B. \& SHAW, A.J. (Eds.). Bryophyte Biology. $2^{\mathrm{a}}$ ed. Cambridge, Cambridge University Press.

OLIVEIRA H. C., BASTOS C. J. P. Jungermanniales (Marchantiophyta) da Chapada da Ibiapaba, Ceará, Brasil. Acta Botanica Brasilica 2009, vol.23, n.4, pp.1202-1209. ISSN 01023306

LISBOA, R. C. L. Musgos acrocárpicos do estado de Rondônia. - Belém: Museu Paraense Emilio Goeldi, 1993.

MIRANDA, T. S. FILHO, J. M. NEVES, B. B. B. BARBOSA, J. A. Estudo do Comportamento Geológico-Estrutural dos Depósitos Cretácicos do Sistema Aquífero Apodi, Bacia Potiguar, NE do Brasil. Estudos Geológicos, v. 22(1), 2012.

PÔRTO, K. C., SILVEIRA, M. F. G. A., SÁ, P S. A. Briófitas da caatinga 1: Estação Experimental do IPA, Caruaru - PE. Acta Botanica Brasilica., Jul 1994, vol.8, no.1, p.77-85. ISSN 0102-3306

PÔRTO, K. C. BEZERRA, M. F. Briófitas de caatinga: 2. Agrestina, Pernambuco, Brasil. Acta Botanica Brasilica. Jul 1996, vol.10, no.1, p.93-102. ISSN 0102-3306

RAVEN, P.H., EVERT, R.F. \& EICHHORN, S.E., Biologia Vegetal. 6.ed. Rio de Janeiro: Guanabara Koogan, 2001. 906p.

SHARP, A.J.; CRUM, H. \& ECKEL, P. 1994. The moss flora of Mexico. Memoirs of The New York Botanical Garden 69: 1-1113.

SILVA, J. B., GERMANO, S. R. Bryophytes on rocky outcrops in the caatinga biome: a conservationist perspective. Acta Botanica Brasilica Dec 2013, vol.27, no.4, p.827-835. ISSN 0102-3306

SHAW, A.J. \& GOFFINET, B. Bryophyte Biology. Cambrige: Cambrige University Press, 2000.

VALENTE, E.B., PÔRTO, K. 2006. Hepáticas (Marchantiophita) de um fragmento de Mata Atlântica da Serra da Jibóia, Munícipio de Santa Teresinha, BA, Brasil. Acta Botanica Brasilica 20(2):433-441

VALENTE, E.B. 2010. Diversidade de briófita na Chapada Diamantina, Bahia, Brasil. Tese de Doutorado. Recife-PE. UFPE.

VALENTE, E. B., PÔRTO, K. \& BASTOS, C.J. 2013. Species richness and distribution of bryophytes within different phitophysiognomies in the Chapada Diamantina region of Brazil. Acta de Botanica Brasilica 27(2): 294-310.

YANO, O. C., AUSTHER G. Briófitas do parque nacional de sete quedas, Guaíra, PR, Brasil. Acta Botanica Brasilica, Ago 2000, vol.14, no.2, p.215-242. ISSN 0102-3306 